\title{
Angle Effect to Dropping of Dew in Closed Suction Catheters
}

\author{
Kazuto Doi', Mayumi Doi'2, Yukoh Yaegashi' ${ }^{3}$, Katsuhisa Imoto ${ }^{3}$, \\ Masaru Ando ${ }^{4}$, Junichi Kadota ${ }^{4}$
}

${ }^{1}$ Department of Pathophysiology, Faculty of Medicine, Oita University, Oita, Japan

${ }^{2}$ Department of Clinical Pharmacology \& Therapeutics, Faculty of Medicine, Oita University, Oita, Japan

${ }^{3}$ Department of Medical Engineering, Faculty of Health Sciences, Junshin Gakuen University, Fukuoka, Japan

${ }^{4}$ Department of Respiratory Medicine \& Infectious diseases, Faculty of Medicine, Oita University, Oita, Japan

Email:m16d9017@oita-u.ac.jp

How to cite this paper: Doi, K., Doi, M., Yaegashi, Y., Imoto, K., Ando, M. and Kadota, J. (2018) Angle Effect to Dropping of Dew in Closed Suction Catheters. Health, 10, 719-729.

https://doi.org/10.4236/health.2018.106055

Received: April 4, 2018

Accepted: June 2, 2018

Published: June 5, 2018

Copyright $(9) 2018$ by authors and Scientific Research Publishing Inc. This work is licensed under the Creative Commons Attribution International License (CC BY 4.0).

http://creativecommons.org/licenses/by/4.0/ (c) (†) Open Access

\begin{abstract}
Intratracheal aspiration in a patient on ventilation is generally performed using a catheter. Of late, closed suction systems have been used more frequently than open systems. To remove tracheal secretions through the intratracheal tube, catheter suction is used, and the suction catheter may be of the closedor open-type. The catheters are cleaned by flushing with sterile $0.9 \%$ saline, resulting in dropping of dew. This phenomenon is caused by some factors: influence of flow, clogging of the suction tube, problem of manipulation of flushing and angle between the intubation tube and the connection port. But this dropping has not yet been investigated. In this study, we focused at this angle and we used the test lung which is simulated machine on behalf of patient. We consider two situations adult and child, also two types of catheters Eco-Cath and Ty-care. In child case we consider elbow-type suction catheters and Y-connector type. The angle was set at $0^{\circ}, 20^{\circ}, 40^{\circ}, 60^{\circ}$, and $90^{\circ}$, and we observed the difference between Eco-Cath and Ty-care. In adults difference is significant ( $\mathrm{p} \ll 0.001$ ), In $90^{\circ}$ between Tracheal intubation and Tracheotomy $(\mathrm{p} \approx 0.26)$. In child difference is significant $(\mathrm{p} \ll 0.001)$, In $90^{\circ}$ between Tracheal intubation and Tracheotomy $(\mathrm{p} \approx 0.15)$. In child case we observed dependency of angle on various conditions too. The relation of the angle and dew was clarified.
\end{abstract}

\section{Keywords}

Catheters, Intratracheal, Intubation, Respiration, Suction, Tracheostomy, Ventilators

\section{Introduction}

Acute- and chronic-phase tracheal aspiration is widely practiced in the hospital 
and home medical care settings by medical professionals as well as non-medical personnel [1] [2]. The procedure and technique are relatively simple, and do not require elaborate equipment or complicated devices. In actual clinical situations, tracheal aspiration rarely poses any risk to the patient's life [3]. However, in order to standardize the technique, the guidelines for tracheal aspiration in adults (during tracheal intubation, tracheostomy, etc.) were formulated in 2007 [2].

There are two types of suction methods: open- and closed-suction. In general, the use of open suction has been more prevalent. However, with the widespread use and adherence to the guidelines in recent years, there has been an increasing use of the closed suction systems for tracheal aspiration [4], because they have a number of advantages over open suction systems. For instance, at least six benefits of using the closed suction system have been reported [5]: it 1) avoids hypoxic conditions by disconnecting the respiratory circuit, 2) avoids release of positive end-expiratory pressure (PEEP), 3) avoids splashing of secretions, 4) avoids the need for standard precautions for each aspiration, 5) reduces aspiration time, and 6) decreases the number of expendables for aspiration. In addition, it has been reported that the closed suction system limits loss in lung volume and oxygenation compared to the open suction system [6] [7]. For these and other reasons, the American Association for Respiratory Care (AARC) created and reported guidelines regarding suction methods in home-care patients [8]. However, another set of guidelines generated by the Centers for Disease Control and Prevention (CDC) does not specify any preference for the multiuse closed system suction catheter or the single-use open system suction catheter for the prevention of pneumonia [9]. Hence, considering the cost, the former (closed suction catheter) is generally used in medical facilities as well as in home-care patients.

There have been several reports on issues that need to be taken care of during tracheal aspiration, such as, an assessment to judge whether the patient adapts to tracheal aspiration, and postural drainage before tracheal aspiration. In addition, several complications associated with tracheal aspiration have been reported [10] such as patient discomfort, elevation of intracranial pressure, and coronary artery spasm. It may be possible that the dew dropping on flushing during tracheal aspiration causes those complications. However, so far, no study has investigated the effect of ventilation and structure of the catheter on the dropping of dew during tracheal aspiration. Therefore, in this study, we simulated a patient on ventilation and investigated the cause of dropping of dew in the closed-type aspiration catheter.

\section{Methods}

\subsection{Materials}

The following suction catheters were used in this study: Eco-Cath for adults 12 Fr (4 mm; for intubation and tracheostomy, Covidien, Japan), Ty-care for adults 12 Fr (4 mm; for intubation and tracheostomy, Covidien, Japan), Eco-Cath el- 
bow type $6 \mathrm{Fr}$ for children $(2.0 \mathrm{~mm}$; for intubation and tracheostomy, Covidien, Japan), Eco-Cath Y connector type for children 6 Fr $(2.0 \mathrm{~mm}$; for intubation and tracheostomy, Covidien, Japan).

\subsection{Experimental Procedures}

Figure 1 shows the circuit diagram of the procedure. Briefly, the test lung (adults: Siemens Maquet Adult 1 Liter Ventilator Test Lung 190 \# 6006832; children: test bag R5, IMI, Japan) was placed vertically, and a ventilator (VELA, Care Fusion 207, America) was connected to simulate a patient on ventilation. The ventilation volume of the ventilator was measured using Flow analyzer PF-300 (imt medical, Switzerland). After aspiration with the closed-type suction catheter, the Eco-Cath or Ty-care, flush operation was carried out using syringe SS-10ESZ10 $10 \mathrm{~mL}$ (Terumo, Japan) and DARTM Saline Vial 0.9\% Sodium Chloride Solution for irrigation $15 \mathrm{ml}$ (Covidien, Japan). A suction device Minic W-II (Shinei Industry Co. Ltd., Japan) was used for producing suction pressure. The state of the dropping was verified by visual observation, with the intubation tube making an angle of $0^{\circ}, 20^{\circ}, 40^{\circ}, 60^{\circ}$, or $90^{\circ}$ with the connection port of the test lung. The ventilator settings were as follows: volume control continuous mandatory ventilation (VC-CMV), $\mathrm{FiO}_{2} ; 21 \%$, breathing frequency; 15 breaths/min, inspiratory time; $1.4 \mathrm{~s}$, PEEP; $0,5,7$, and $10 \mathrm{~cm} \mathrm{H}_{2} \mathrm{O}$, and tidal

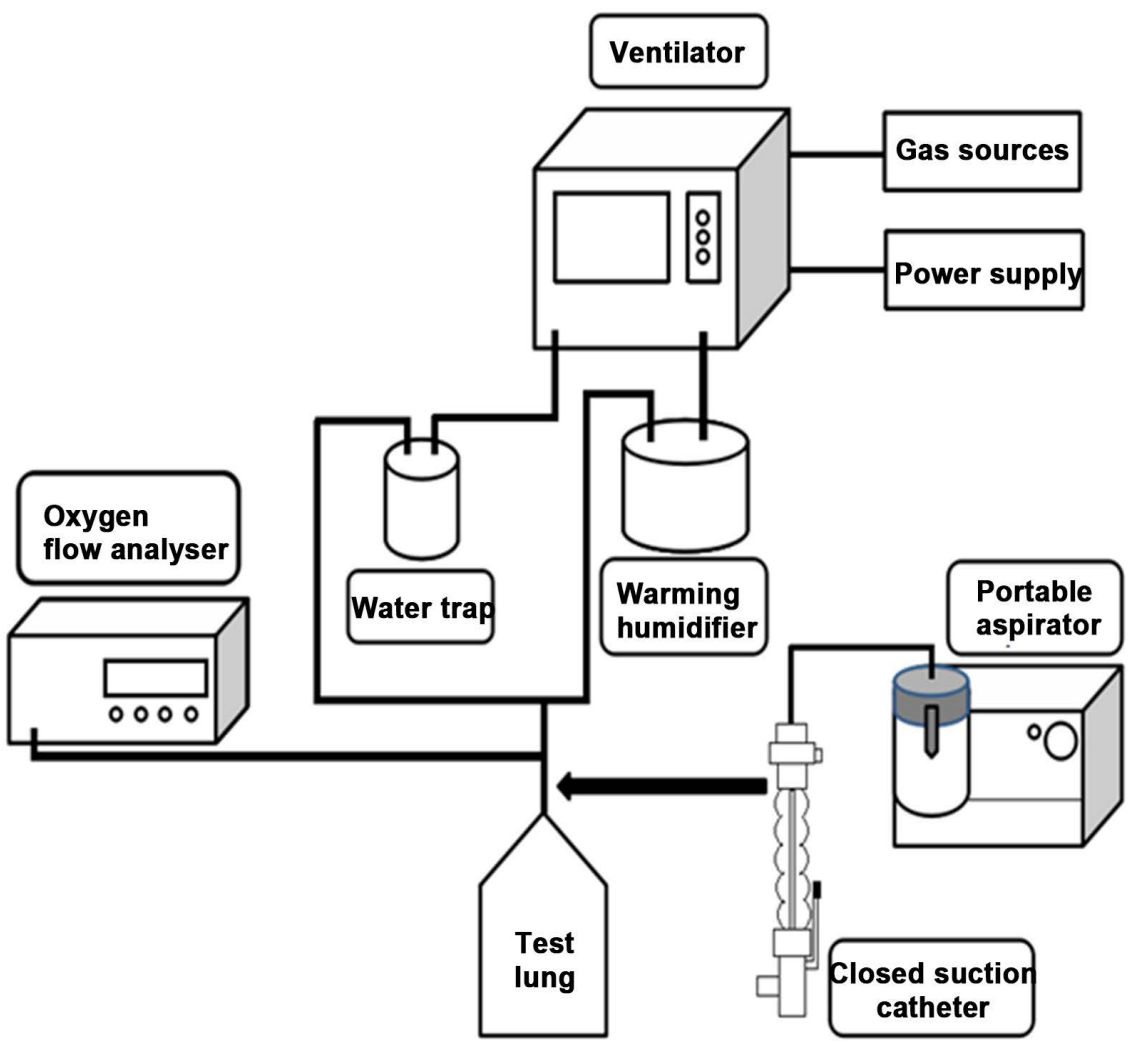

Figure 1. The circuit diagram. The test lung was placed vertically, and a ventilator was connected to simulate a patient on ventilation. 
volume; $100 \mathrm{ml}, 300 \mathrm{ml}$, and $500 \mathrm{ml}$. In positive control continuous mandatory ventilation (PC-CMV), the pressure support value was varied in the range of 13 $38 \mathrm{~cm} \mathrm{H}_{2} \mathrm{O}$ depending on the tidal volume.

A suction pressure of $20 \mathrm{kPa}(150 \mathrm{mmHg})$ was applied, in accordance with the clinical guidelines followed in Japan.

\subsection{Statistics}

All statistical analyses were performed with $\mathrm{R}$ (The R Foundation for Statistical Computing, Vienna, Austria). The Chi-squared test was used to check dependence between the time of dropping and each factor. Additionally, Fisher's exact test was used when the Chi-squared test could not be used. For each angle between the intubation tube and the connection port of the test lung, Chi-squared or Fisher's exact tests were conducted to investigate the relationship between "presence/absence of dropping" and "tidal volume", "control method", "type of catheter", and "PEEP". P $<0.01$ was considered statistically significant.

\section{Results}

\subsection{Adults}

In adults, dew droppings were observed in 67 of all 1440 times in VC-CMV and 93 of all 1440 times in PC-CMV; the dropping was more frequent in PC-CMV. Table 1 shows the relationship between the dropping time and angle of intubation relative to the connection port. Our results showed a significant relationship between the number of droppings and the angle between the intubation tube and the connection port of the test lung $(\mathrm{P}<0.001$, chi-squared test). The last two rows in Table 1 shows the result of chi-squared test between the dropping and angle for "tracheal intubation $90^{\circ}$ " and "tracheotomy $90^{\circ}$ ". The type of catheter and the number of dropping had a significant relationship at angles of $40^{\circ}$ to $90^{\circ}$ (Table 2). With regards to the structure of the catheter, droppings were

Table 1. The number of droppings at each angle (adults).

\begin{tabular}{ccccc}
\hline \multirow{2}{*}{ Angle } & \multicolumn{3}{c}{ dropping } & p-value \\
\cline { 2 - 3 } & Yes & None & Total & \\
\hline Tracheal intubation & 3 & 477 & $480.001^{*}:$ \\
$0^{\circ}$ & 10 & 470 & 480 & \\
$20^{\circ}$ & 16 & 464 & 480 & \\
$40^{\circ}$ & 24 & 456 & 480 & \\
$60^{\circ}$ & 48 & 432 & 480 & $0.26 \dagger$ \\
$90^{\circ}$ & 59 & 421 & 480 & \\
\hline Tracheotomy $90^{\circ}$ & & & & \\
\hline
\end{tabular}

*: Significance with the chi-squared test. $\dagger$ : Probability (by chi-square test) between tracheal intubation $90^{\circ}$ and tracheotomy $90^{\circ}$. 
Table 2. The p-value of each angle under different conditions (adults).

\begin{tabular}{ccccccc}
\hline & \multicolumn{5}{c}{ Tracheal intubation } & \multicolumn{2}{c}{ Tracheotomy } \\
\cline { 2 - 7 } & $0^{\circ}$ & $20^{\circ}$ & $40^{\circ}$ & $60^{\circ}$ & $90^{\circ}$ & $90^{\circ}$ \\
\hline Ventilation ${ }^{*}$ & 0.78 & 0.78 & 0.43 & 1.00 & 0.54 & 0.98 \\
Control method $\dagger$ & 1.00 & 0.34 & 0.45 & 0.53 & 0.45 & 0.40 \\
Catheter $\ddagger$ & 0.25 & $\mathbf{0 . 0 0 2}$ & $<0.001$ & $<0.001$ & $<0.001$ & $<0.001$ \\
PEEP§ & 0.62 & 0.71 & 0.07 & $\mathbf{0 . 0 0 9}$ & 0.34 & 0.08 \\
\hline
\end{tabular}

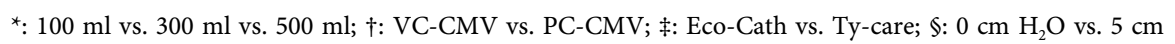
$\mathrm{H}_{2} \mathrm{O}$ vs. $7 \mathrm{~cm} \mathrm{H} \mathrm{H}_{2} \mathrm{O}$ vs. $10 \mathrm{~cm} \mathrm{H}_{2} \mathrm{O}$.

observed 0 out of 1440 times in the Ty-care, and 160 out of 1440 times in the Eco-Cath; and this difference was statistically significant $(\mathrm{P}<0.001)$.

\subsection{Children}

The droppings were observed 61 of 1080 times in VC-CMV and 66 of 1080 times in PC-CMV; and like the observation in adults, the difference was not significant. Additionally, as was observed in adults, there was a correlation between the number of dropping and the angle between the intubation tube and the connection port of the test lung in the children (Table 3). There was a significant relationship between the presence/absence of dropping and the angle between the intubation tube and the connection port of the lung $(P<0.001)$. At an angle of $90^{\circ}$ (tracheal intubation and tracheostomy), there was a significant association between the type of the catheter placement and the number of droppings (Table 4). At all angles from $20^{\circ}$ to $90^{\circ}$, the dropping of dew was observed more frequently in the elbow-type suction catheter $(98 / 1080)$ than in the Y-connector type catheter (29/1080).

\section{Discussion}

Approximately ten years have passed since Japan's guidelines for tracheal aspiration (first edition) were introduced in 2007. In keeping with the medical situation regarding the use of tracheal aspiration, these guidelines were revised in 2013 [2]. The overall evidence level was reviewed and the recommendation level was represented by the grade classification [11]. Following a standardized procedure according to the recommended guidelines has been shown to decrease the occurrence of complications, such as rise in blood pressure, increased heart rate, decreased oxygen saturation and carbon dioxide storage [12]. Hence, the importance of standardized protocols to perform this procedure is well-known. In this study, tracheal aspiration was performed according to the established guidelines by the same operator so that all suction procedures were performed under identical conditions.

In adults, dew dropping was found to be more frequent in PC-CMV than in VC-CMV. As the angle between the intubation tube and the connection port of the test lung increased, the numbers of dropping increased. It is noteworthy that 
Table 3. The number of droppings at each angle (children).

\begin{tabular}{ccccc}
\hline \multirow{2}{*}{ Angle } & \multicolumn{3}{c}{ dropping } & p-value \\
\cline { 2 - 4 } & Yes & None & Total & $<0.001^{*}:$ \\
\hline Tracheal intubation & 0 & 360 & 360 & \\
\hline $0^{\circ}$ & 1 & 359 & 360 & \\
$20^{\circ}$ & 6 & 354 & 360 & \\
$40^{\circ}$ & 12 & 348 & 360 & \\
$60^{\circ}$ & 49 & 311 & 360 & $0.15 \dagger$ \\
$90^{\circ}$ & 59 & 301 & 360 & \\
Tracheotomy $90^{\circ}$ & & & & \\
\hline
\end{tabular}

*: Significance with the chi-squared test. $\dagger$ : Probability (by chi-square test) between tracheal intubation $90^{\circ}$ and tracheotomy $90^{\circ}$.

Table 4. The p-value of each angle under different conditions (children).

\begin{tabular}{ccccccc}
\hline & \multicolumn{5}{c}{ Tracheal intubation } & Tracheotomy \\
\cline { 2 - 7 } & $0^{\circ}$ & $20^{\circ}$ & $40^{\circ}$ & $60^{\circ}$ & $90^{\circ}$ & $90^{\circ}$ \\
\hline Ventilation* & 1.00 & 1.00 & 0.61 & 0.77 & 0.79 & 0.22 \\
Control method $\dagger$ & 1.00 & 1.00 & 0.68 & 1.00 & 0.54 & 0.39 \\
Catheter $\neq$ & 1.00 & 1.00 & 0.21 & 0.040 & $<0.001$ & $<0.001$ \\
PEEP§ & 1.00 & 1.00 & 1.00 & 0.063 & 0.59 & 0.058 \\
\hline
\end{tabular}

*: $100 \mathrm{ml}$ vs. $300 \mathrm{ml}$ vs. $500 \mathrm{ml} ; \dagger:$ VC-CMV vs. PC-CMV; $\ddagger$ : Eco-Cath vs. Ty-care; $\S: 0 \mathrm{~cm} \mathrm{H} \mathrm{H}_{2} \mathrm{O}$ vs. $5 \mathrm{~cm}$ $\mathrm{H}_{2} \mathrm{O}$ vs. $7 \mathrm{~cm} \mathrm{H} \mathrm{H}_{2} \mathrm{O}$ vs. $10 \mathrm{~cm} \mathrm{H}_{2} \mathrm{O}$.

on flushing at an angle of $0^{\circ}$, the saline was pulled by suction pressure, so it hardly dripped (Figure 2), while at $90^{\circ}$, because of gravity, all the saline was not pulled by suction pressure, hence, fell on to the side of the patient without being absorbed by the side groove (Figure 3). We have observed this phenomenon previously and presented it at the Chubu clinical engineering society in Nagoya, 2012. The Ty-care was not considerably influenced by the airflow during flushing. However, it does not imply absence of possibility of dropping. A disadvantage of the structure of the Ty-care is that the saline that cannot be sucked by the catheter during flushing accumulates under the rotary valve and may drop on to the side of the patient at the time of valve rotation. In this study, the experimenters were familiar with the drawbacks of Ty-care and the dropping did not happen because they were careful to avoid it.

In children, dropping was observed equally frequently in PC-CMV and VC-CMV. The number of dropping increased as the angle between the intubation tube and the connection port of the test lung increased. The total number for children was less than that for adults because some of the experiments with $\mathrm{Vti}$ at $500 \mathrm{ml}$ were not counted. When Vti reached $500 \mathrm{ml}$, the airway internal pressure exceeded $40 \mathrm{~cm} \mathrm{H}_{2} \mathrm{O}$, which is not compatible with clinical practice. 
(a)

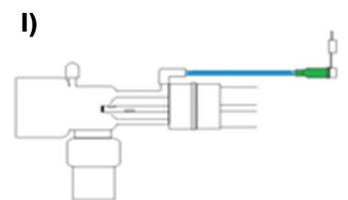

(b)
II)

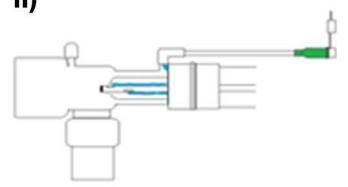

III)

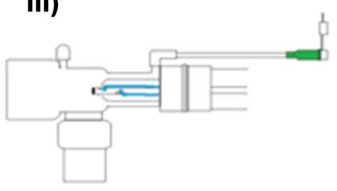

IV)

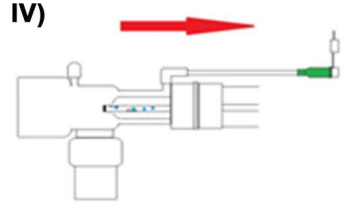

V)

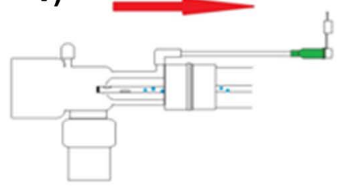

VI)

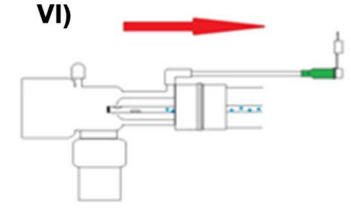

Figure 2. The movement of the saline at an angle of $0^{\circ}$ between the intubation tube and the connection port of the test lung. (a) Patient side; (b) Connection port of the respiratory circuit. The part painted blue indicates saline and the red arrow indicates suction pressure. Presumably, on flushing at an angle of $0^{\circ}$, saline is pulled by suction pressure, so it hardly drips.

I)

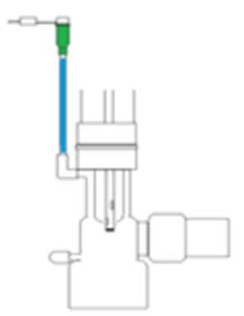

(a)

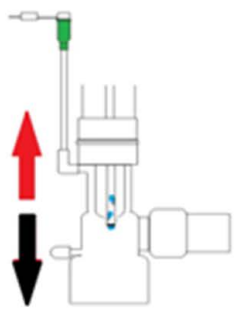

II)
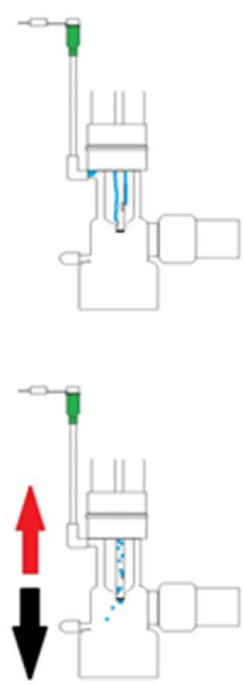

III)
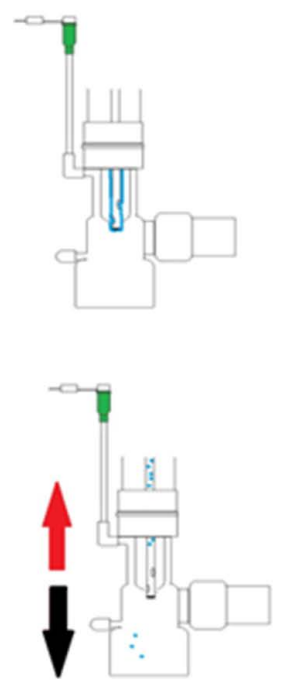

Figure 3. The movement of the saline at an angle of $90^{\circ}$ between the intubation tube and the connection port of the test lung. (a) Patient side. The part painted blue indicates saline. The red arrow indicates suction pressure and the black arrow shows gravity. At $90^{\circ}$, because of gravity, the entire saline is not pulled by suction pressure, and hence, falls onto the patient's side.

The Y connector type catheter was contained in a cylinder when flushed, and saline was sucked into the side groove. In contrast, the elbow-type catheter is structured to be exposed to flow because the catheter edge length was approximately $5 \mathrm{~mm}$ for adults and $3 \mathrm{~mm}$ for children, and hence was susceptible to flow (Figure 4).

Three other factors affecting the dropping of dew from the closed-type suction catheter are worth mentioning. The first is "problem of flow". Physiological saline was exposed to ventilation and it dropped onto the side of the patient when 


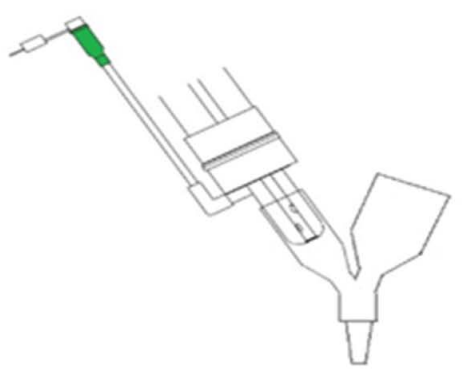

Y connector type

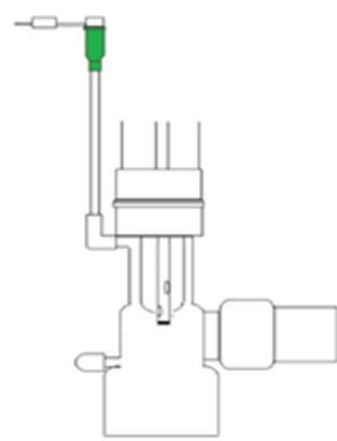

elbow type

Figure 4. The structure of the Y-connector type catheter and the elbow-type catheter. The $\mathrm{Y}$-connector type catheter is contained in a cylinder when flushed, and saline is sucked into the side groove. The elbow-type catheter is structured to be exposed to flow. Because the catheter edge length is approximately $5 \mathrm{~mm}$ for adults and $3 \mathrm{~mm}$ for children, and hence, is susceptible to flow.

flushed (Figure 5). There is no prior research report on this, to our knowledge. The numbers of the droppings in this study was less than that previously reported by Doi (the Chubu clinical engineering society 2012, Nagoya). The performance of the ventilator used in this study (VELA) was better than that of the ventilator (LTV 1200) used in previous studies for the chronic phase. For the flow and the ventilation, VELA was more accurate than other ventilators such as LTV1200. In this context, Banner et al have shown that the ventilator used in the acute phase was more precise and had a better function than the ventilator used in the chronic phase [13].

The second issue is "clogging of the suction tube". As in the AARC guidelines, suction was usually performed within $10 \mathrm{~s}$ at $20 \mathrm{kPa}(150 \mathrm{mmHg})$. However, as sputum remained in the catheter or the suction bottle became full, the suction power decreased and the flush operation may not be performed normally, resulting in dropping of the saline on to the side of the patient. This was also mentioned in the 24th report of the medical accident information gathering project [3], and is suggested as a risk of flushing caused by a decrease in suction power.

The third issue is "problems related to the procedure". According to the guideline, when cleaning the lumen of the catheter, 5 to $10 \mathrm{ml}$ of saline needs to be injected from the washing solution injection port while applying negative pressure, but the injection speed of saline is not specified. It was thought that the number of dropping was small when injecting at about $1 \mathrm{ml}$ per second. It is expected that the risk of the dropping will increase as the amount of saline per second increases.

We believe that dropping in this study occurred partially due to influence of flow, clogging of suction tube, and problems related to the procedure. Similar results have been reported in the Japan Council for Quality Health Care Medical Accident Information Collection Project [3]. It is difficult to completely eliminate the influence of the operator's lack of experience and knowledge. Additionally, there 

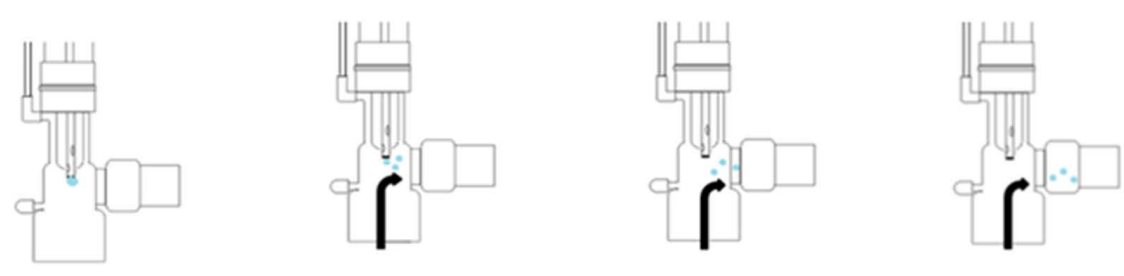

\section{Expiration}

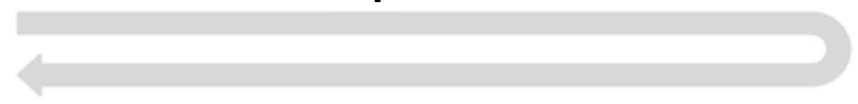

Inspiration
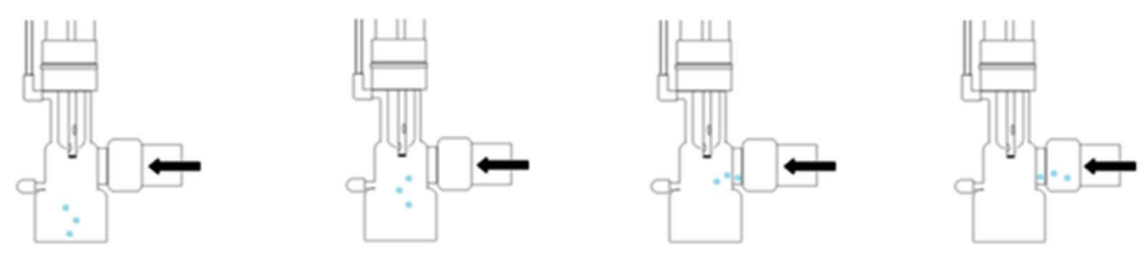

Figure 5. Influence of flow. The upward arrow indicates expiration by the patient and the left-pointing arrow indicates the inspiration from the ventilation. Saline was exposed to ventilation and it dropped onto the patient's side when flushed.

is the possibility of potentially serious medical errors if the procedure is performed manually, and there is no solution other than adequate training of the medical staff. However, it is possible to alter the structure of the catheter so that events do not occur irreversibly. Compared with the Eco-Cath, this study found that the structure of the Ty-care can prevent factors of dropping, such as influence of angle on flushing, influence of airflow, clogging of the suction tube, and errors in the procedure by the operator.

This study has provided important information about tracheal aspiration, which is carried out in domestic clinical sites. However, it does have some limitations. First, the aspirator used in this study was not equipped, but a portable aspirator. Unlike the pressure of the piping used in hospital facilities, the suction pressure becomes unstable and the number of dropping may increase. The risks related to suction pressure will decrease if stable piping is used at hospital facilities. Second, the evaluation of dropping was subjective. It can be said that it is preferable to objectively evaluate the dropping using moving images or the like. Third, it cannot be denied that since this was a simulation study and was not performed on a real patient, some causes of dropping may not have been identified. Performing this study under actual clinical conditions will increase our knowledge on preventing dropping. These considerations will constitute the rationale for future studies.

\section{Conclusion}

In this study, we investigated the causes of dropping of dew during saline flush in closed-type suction catheters. Various factors affect this dropping: the structure of the catheter, the influence of flow by the ventilator during the acute 
phase, clogging of the suction tube, and problems related to the procedure. But in this research, we clarified relation of the angle and dew. Especially, between the intubation tube and the connection port of the test lung at the time of flushing. These results provide valuable information regarding the risk factors for dropping at the time of tracheal aspiration, and will be useful in guiding these procedures in clinical practice.

\section{Acknowledgements}

We would like to thank Editage (http://www.editage.jp) for English language editing.

\section{References}

[1] Ministry of Health, Labour and Welfare of Japan Website (2017). (In Japanese) http://www.mhlw.go.jp/stf2/shingi2/2r9852000000g3ig-att/2r9852000000iiut.pdf

[2] Japanese Society of Respiratory Care Medicine Website (2017). (In Japanese) http://square.umin.ac.jp/jrcm/pdf/kikanguideline2013.pdf

[3] Japan Council for Quality Health Care Website (2017). (In Japanese) http://www.med-safe.jp/pdf/report_24.pdf

[4] Shizuoka Hospital Association Website (2017). (In Japanese) http://shizuoka-bk.jp/advice/detail.php?N=68

[5] Michimata, Y. (2014) Shin Jinkou Kokyuu Kea No Subete Ga Wakaru Hon. [A Book That Shows All about Artificial Respiration.] Shorinsha, Japan.

[6] Corley, A., Sharpe, N., Caruana, L.R., Spooner, A.J. and Fraser, J.F. (2014) Lung Volume Changes during Cleaning of Closed Endotracheal Suction Catheters: A Randomized Crossover Study Using Electrical Impedance Tomography. Respiratory Care, 59, 497-503. https://doi.org/10.4187/respcare.02601

[7] Cereda, M., Villa, F., Colombo, E., Greco, G., Nacoti, M. and Pesenti, A. (2001) Closed System Endotracheal Suctioning Maintains Lung Volume during Volume-Controlled Mechanical Ventilation. Intensive Care Medicine, 27, 648-654. https://doi.org/10.1007/s001340100897

[8] Guideline, A.C.P. (1999) Suctioning of the Patient in the Home. Respiratory Care, 44, 99-104.

[9] Tablan, O.C., Anderson, L.J., Besser, R., Bridges, C., Hajjeh, R. and CDC, Healthcare Infection Control Practices Advisory Committee (2004) Guidelines for preventing Health-Care-Associated Pneumonia, 2003: Recommendations of CDC and the Healthcare Infection Control Practices Advisory Committee. MMWR Recommendations and Reports, 53, 1-36.

[10] Michimata, Y., Kozu, R. and Kotani, T. (2009) Jinkou Kokyuu Kanri Jissen Gaido. [Practice Guide for Artificial Respiration Management.] Shorinsha, Japan.

[11] Guyatt, G.H., Oxman, A.D., Vist, G.E., Kunz, R., Falck-Ytter, Y., Alonso-Coello, P., et al. (2008) GRADE: An Emerging Consensus on Rating Quality of Evidence and Strength of Recommendations. BMJ, 336, 924-926. https://doi.org/10.1136/bmj.39489.470347.AD

[12] Celik, S.S. and Elbas, N.O. (2000) The Standard of Suction for Patients Undergoing Endotracheal Intubation. Intensive and Critical Care Nursing, 16, 191-198. https://doi.org/10.1054/iccn.2000.1487 
[13] Banner, M.J., Blanch, P.B. and Kirby, R.R. (1993) Imposed Work of Breathing and Methods of Triggering a Demand-Flow, Continuous Positive Airway Pressure System. Critical Care Medicine, 21, 183-190.

https://doi.org/10.1097/00003246-199302000-00007 